\title{
A comparative study of the cloudy apple juice sterilized by high-temperature short-time or high hydrostatic pressure processing: shelf-life, phytochemical and microbial view
}

\author{
Hong DENG ${ }^{1,2.3}$, Peng-Tao ZHAO ${ }^{1,2.3^{*}}$, Tian-Ge Yang ${ }^{1}$, Yong-Hong MENG ${ }^{1,2.3^{*}}$ (D)
}

\begin{abstract}
Cloudy apple juice (CAJ) is popular due to its potential health benefits and pleasant flavor. However, the common used sterilization methods of CAJ by High hydrostatic pressure (HHP) or high-temperature short time (HTST) still showed many inadequacies. The present work studied the impact of HHP $\left(400 \mathrm{MPa} / 10^{\circ} \mathrm{C} / 10 \mathrm{~min}\right)$ and $\mathrm{HTST}\left(98^{\circ} \mathrm{C} / 50 \mathrm{~s}\right)$ on CAJs made from a new cultivar Changfu 2 planted in Loess plateau area. We comparatively evaluated the microbes inactivation, enzymatic activity, phytochemical parameters, and sensory quality after the HHP and HTST treatment and during the cold storage $\left(4^{\circ} \mathrm{C}\right)$. Results showed that during the cold storage, both HHP and HTST treated CAJ showed a declining trend in sensory attributes like aroma, taste and overall acceptability. HTST showed a higher killing rate of bacteria, and the CAJ was detected a higher diversity of microorganisms (expressed as OTU) during the cold storage. At the end of shelf-life, Rickettsia, oxyphotobacteria, and pseudomonas were detected as the dominant genera in both HHP and HTST treated CAJs. Spearman bivariate correlate analysis determined the relationship between the bacterial profiles and enzymatic activity, phytochemical parameters, and sensory quality after the HHP and HTST treatment.
\end{abstract}

Keywords: cloudy apple juice; shelf life; high hydrostatic pressure sterilization; high-temperature short-time sterilization.

Practical Application: This study is providing theoretical foundations for commercial cloudy apple juice producers to choose HTST or HHP treatment according to the demands.

\section{Introduction}

Cloudy apple juice (CAJ) is getting more popular due to its potential health benefits and pleasant flavor. Compared with concentrated and reduced apple juice, cloudy apple juice is reported to contain more abundant bioactive compounds, such as phenolic acids, flavonoids, malic acid, tartaric acid, carotenes, and fibers (Oszmiański et al., 2009; Siguemoto et al., 2019). Notably, the bioactive polyphenolic substances (chlorogenic acid and phlorizin) in apple juice are known as effective agents against cardiovascular diseases, diabetes, osteoporosis, and neurodegenerative diseases. However, a great industry challenge is that the shelf life of CAJ juice is short, even less than 30 days. Microbial spoilage, enzymatic browning, flavor loss, and fast sedimentation are the main challenges to extend shelf life of CAJ (Oszmiański et al., 2009; Stinco et al., 2019).

Understanding that microbes, enzyme, irregularly shaped particles, polymerized phenolic compounds, as well as flavor compounds are reactive, the CAJ industries are hunting for ways to make them more stable. Sterilization process is playing a significant role in the phytochemical profiles and organoleptic characteristics of CAJ product as well as its shelf life. Currently, conventional sterilization technologies (such as pasteurization) and high-temperature short time (HTST) are still the main strategies of microorganism inactivation in the juice industry. Pasteurization $\left(80 \sim 90{ }^{\circ} \mathrm{C}, 10 \sim 30 \mathrm{~min}\right)$ is regarded as an effective way to control the enzymes that negatively affect the quality of juice products, maintaining the safety and shelf-stability of juice. However, excessive thermal treatments will inevitably exacerbate nutritional and fresh quality losses. In recent decades, there is an increasing interest in innovative non-thermal approaches alternative to thermal treatment. Certain non-thermal technologies, such as high hydrostatic pressure (HHP) (Varela-Santos et al., 2012), highpressure homogenization (HPH) (Alvarez-Sabatel et al., 2015), pulse electric field (PEF) (Katiyo et al., 2017), and cold plasma (Illera et al., 2019) are showing advantages and being applied to control the juice quality in many researches. In which, HHP treatment is the most utilized technology (Zou et al., 2016).

The application of HTST or HHP treatment in apple juice has been well documented in the literatures, in which, the authors have demonstrated the effectiveness of HHP or HTST treatment in inactivating microorganisms in apple juice (Yi et al., 2017). For example, HHP treatment $\left(500 \mathrm{MPa} / 3 \mathrm{~min} / 25^{\circ} \mathrm{C}\right)$ was sufficient to reduce the total aerobic bacteria, and coliforms population level in cloudy apple juice below the detection limit $(<1 \mathrm{CFU} / \mathrm{g})$ and no microbial growth was observed throughout the storage period of 21 days at $4{ }^{\circ} \mathrm{C}$ (Kim et al., 2012). However, the main microorganism profile and the quantify changes of apple juice over the shelf-life remains unclear. Since the 
microorganisms cannot be killed completely and enzymes of juice were not inactivated totally, quality deterioration of CAJ is inescapability. Besides, few literatures have comparatively studied the cloudy apple juice after HTST and HHP processing from the physicochemical, enzymatic and microbial view. More research on the correlations between physicochemical parameters like polyphenol profiles, volatile profiles and the sensory attributes of CAJ, correlations between enzyme activity and color parameters of CAJ, are very helpful to understand the mechanism of quality changes during the storage. In particular, the main microorganism profile of CAJ during storage remains unclear, which are more important factors determining the shelf-life. Moreover, revealing the correlations between bacterial community and the physicochemical parameters are also in urgent need to design the proper sterilization method according to the juice constituents.

In these regards, the present study aims to evaluate the shelf-life of cloudy apple juice under HTST and HHP processing in terms of microbial, physicochemical, and flavor quality. This study is providing theoretical foundations for commercial cloudy apple juice producers to choose HTST or HHP treatment according to the demands.

\section{Material and methods}

\subsection{Cloudy apple juice preparation}

Fresh Fuji apples, which were uniform in size, without mechanical damage or rot, were purchased from a local market. The apples were peeled and cut into pieces after being washed, and the stems and seeds were discarded. L-Ascorbic acid $(0.5 \% \mathrm{w} / \mathrm{v})$ and $\mathrm{CaCl}_{2}$ solution $(0.25 \% \mathrm{w} / \mathrm{v})$ were added during processing. Juices were extracted using an $\mathrm{HU}-780 \mathrm{WN}$ juicer (Hurom Electric Appliance Co., Seoul, Korea) and filtered to remove tissue residues using a 100-mesh filter.

\subsection{Chemicals and reagents}

Gallic acid, caffeic acid, 4-hydroxy benzoic acid, catechin, epicatechin, rutin, quercetin, chlorogenic acid, and phlorizin used for HPLC characterization were purchased from Sigma-Aldrich (Beijing, China). ( \pm )-6-Hydroxy-2,5,7,8- tetramethyl- chroman2-carboxylic acid (Trolox), 2,4,6-tri-2-pyridyl-1,3,5-triazine (TPTZ), 2,2-diphenyl-1-picrylhydrazyl (DPPH) for chemical analysis were purchased from Tianjin Fuyu Fine Chemicals Co., Ltd. (Tianjin, China). Plate count agar, VRBA (Violet Red Bile Agar), RBM (Rose Bengal medium) and CTAB (Hexadecyl trimethyl ammonium bromide) were purchased from Aoboxing Biotechnology Co., Ltd. (Beijing, China).

\subsection{HTST treatment}

Cloudy apple juice samples were pasteurized in a laboratoryscale pasteurizer at $98{ }^{\circ} \mathrm{C}$ for $50 \mathrm{~s}$. The pasteurized juices were hot-filled into sterilized glass bottles. The samples were stored at $4{ }^{\circ} \mathrm{C}$ for subsequent analyses after being cooled. All treatments were performed in triplicate.

\subsection{HHP treatment}

The apple juices were processed with a 10-L HHP equipment (HHP.L1-600, Huatai Senyu BIOENG. TECH. Co., Ltd., Tianjin, China). The initial temperature of the sample was $10^{\circ} \mathrm{C}$, and the sample temperature did not exceed $25^{\circ} \mathrm{C}$ throughout the treatment (Baron et al., 2006). The pressurization rate was near $120 \mathrm{MPa} / \mathrm{min}$, and the depressurization time is less than 3 seconds. The optimal conditions of HHP treatment were determined to be $400 \mathrm{MPa}$ for $10 \mathrm{~min}$. The cloudy apple juice sample was filled in $50 \mathrm{~mL}$ polyethylene terephthalate (PET) bottles for HHP treatment. After the HHP processing, all samples were stored at $4{ }^{\circ} \mathrm{C}$ for analysis. All treatments were performed in triplicate.

\subsection{Physical and chemical parameters}

The $\mathrm{pH}$, total soluble solids (TSS) and titratable acidity (TA) of cloudy apple juice samples were determined according to our previous work (Deng et al., 2015). The color of apple juice was measured using a NS800 colorimeter (3NH Technology Co., Ltd., Shenzhen, China) at room temperature referenced by (Cao et al., 2011), which was expressed as the $\mathrm{L}^{*}$ (lightness to darkness), $\mathrm{a}^{\star}$ (redness to greenness) and $\mathrm{b}^{*}$ (yellowness to blueness). L-Ascorbic acid was analyzed according to the 2, 6-dichloroindophenol method (Yen et al., 2002) with modifications.

Yen, G.-C., P.-D. Duh and H.-L. Tsai (2002). "Antioxidant and pro-oxidant properties of ascorbic acid and gallic acid." Food Chemistry 79(3): 307-313.

\subsection{Measurement of PPO and POD}

PPO and POD were extracted and determined according to the method of (Bayındırlı et al., 2006). The absorbance value at the start of the reaction for $15 \mathrm{~s}$ was used as an initial value using a spectrophotometer, and the absorbance at $420 / 470 \mathrm{~nm}$ was recorded every 1 minute thereafter. The PPO/POD enzyme activity was calculated by applying Equation 1:

$U=\frac{\Delta O D_{420 / 470} \times V_{1}}{V_{2} \times m}$

where $V_{1}$ is the total volume of the sample extract $(\mathrm{mL}), \mathrm{V}_{2}$ is the extract volume of the sample taken during the measurement $(\mathrm{mL})$, and $\mathrm{m}$ is the sample mass $(\mathrm{g})$.

\subsection{Measurement of antioxidant activity}

The antioxidant activities, including the capabilities of scavenging free radicals (DPPH) and reducing iron (FRAP), were studied based on the method described by Patras et al. (2009a).

\subsection{Measurement of polyphenol components}

The extraction and determination method of polyphenols in cloudy apple juice was based on our previous study (Deng et al., 2015). Separations were executed on a C18 column (150 x $4.6 \mathrm{~mm}, 5 \mu \mathrm{m}$, Agilent Technologies Inc., Shanghai, China). Agilent 1260 Infinity HPLC system (Agilent Electron Co., Shanghai, China) was used for chromatographic analysis. The detection wavelength was $280 \mathrm{~nm}$, and the injection volume was $10 \mu \mathrm{L}$ during the run. 


\subsection{Measurement of microorganisms}

Plate count agar was used to calculate total aerobic bacteria (TAB) and hatched at $37^{\circ} \mathrm{C}$ for $48 \pm 2 \mathrm{~h}$. Rose Red Agar was used to calculate the feasibility of yeast and mold (Y\&M) after $72 \pm 2 \mathrm{~h}$ incubation at $27^{\circ} \mathrm{C}$. Crystal violet neutral red bile salt agar was used to calculate E. coli incubation at $37^{\circ} \mathrm{C}$ for $48 \pm 2 \mathrm{~h}$ (Gómez-López et al., 2010).

\subsection{Bacterial diversity analysis}

Microbial diversity in HTST and HHP treatment cloudy apple juice samples was determined using PCR-DGGE. Total DNA was rapidly extracted using the Fast Prep method in combination with CTAB (Abdolmaleki et al., 2014). The resulting DNA was dissolved in TE buffer solution and stored at $20^{\circ} \mathrm{C}$ before evaluation. Then, the sequencing library was generated using IonPlus Fragment Library Kit 48 rxns (Thermofisher, Shanghai, China). The library quality was evaluated on the Qubit@2.0 Fluorometer. Finally, the library was sequenced on an Ion S5TM $\mathrm{XL}$ platform. The juice sample sequences processed by CK, HHP, and HTST were clustered into Operational Taxonomic Units (OTUs) with $97 \%$ consistency by default. According to the algorithm principle, sequences with the highest frequency in OTU were selected as the representative sequences of OTU.

\subsection{Sensory evaluation}

Sensory evaluation of apple juice was conducted by a semitrained group during all the shelf life analysis. The sensory panel consisted of 20 experienced panelists (10 females and 10 males) aged at 24-37 years. Panelists were asked to score by the criteria of the score sheet (showed in Table S1 in Supplementary Material) and used the 1-9 feature scale to score color, appearance, aroma, taste and overall acceptability ( 9 is extremely like, 1 is extremely dislike, 5 is the rejection point).

\subsection{Statistical analysis}

Data analysis was performed by ANOVA with Duncan's test using SPSS 20.0 (IBM, Chicago, IL, USA). Figures in this study were drawn by Origin 8.0 (OriginLab, Northampton, MA, USA) software. The results were expressed as mean \pm standard deviation (SD), $\mathrm{p}<0.05$ was considered significant. Principal Component Analysis (PCA) was used as an exploratory technique for assessing each data set to detect potential outliers.

\section{Results and discussion}

\subsection{Effects of HHP and HTST on pH, TSS, TA and L-ascorbic acid parameters}

The overall parameters of CAJ treated by HHP or HTST treatment are comparable to that of fresh apple juice. The $\mathrm{pH}$, TSS, and TA in CAJ samples (data showed in Table S2 in Supplementary Material) showed no significant change after HTST and HHP treatment during 30 days' storage period $(\mathrm{p}<0.05)$. As shown in Table 1 , a higher content of ascorbic acid was obtained in HHP treated cloudy apple juice than in HTST. In the paper of Kim et al. (2012), they also found that HHP treatment did not significantly change vitamin $\mathrm{C}$ content. Compared with HTST treatment, HHP retained more ascorbic acid content in CAJ. However, a sharp drop began at week 2 to week 5 . In contrast, L-ascorbic acid in the HTST sample showed a much slower decrease trend. The possible

Table 1. Changes of ascorbic acid, color parameters, PPO and POD of cloudy apple juice after HTST or HHP treatment during the storage period at $4{ }^{\circ} \mathrm{C}$.

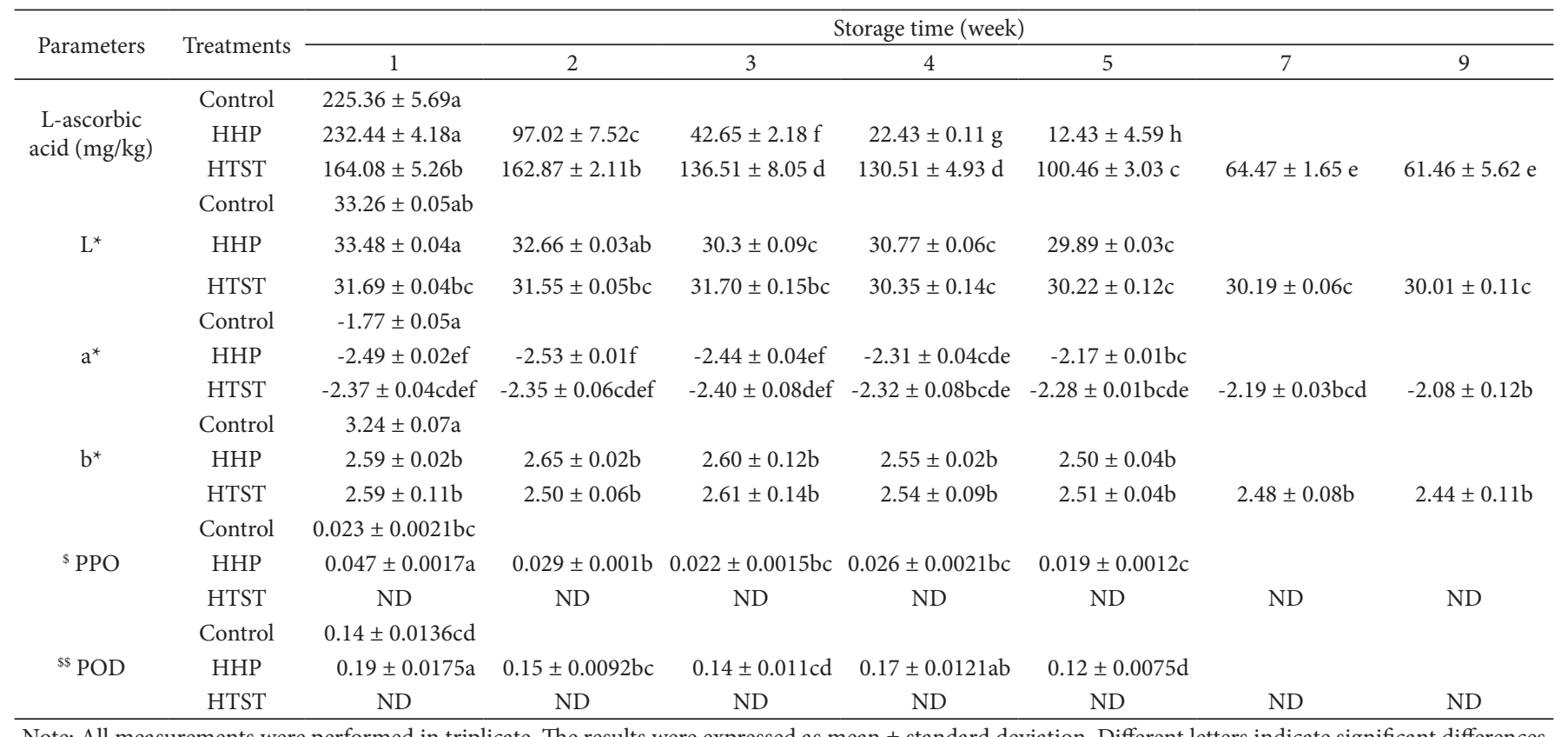

Note: All measurements were performed in triplicate. The results were expressed as mean \pm standard deviation. Different letters indicate significant differences

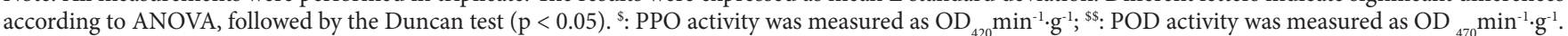


explanations are the HHP-treated CAJ contains more oxygen and related oxidases, making its content decrease faster during the storage period.

\subsection{Enzyme activity}

Scientists believed that series of enzymatic browning reactions occurred during storage time were one of the main reason resulting in a shorter shelf life of juice products (Abid et al., 2014; Jukanti, 2017; Marszalek et al., 2019). The control of enzymatic browning reactions was crucial for manufacturing cloudy apple juice. The effects of HHP and HTST treatment on PPO and POD activities and color parameters $\left(\mathrm{L}^{*}, \mathrm{a}^{*}, \mathrm{~b}^{*}\right.$ values $)$ in cloudy apple juice samples were shown in Table 1. PPO and POD enzymes were inactivated completely by HTST treatment. In contrast, the activities of PPO and POD of the HHP treatment juice were $96 \%$ and $114 \%$, respectively. As reported in some studies, PPO and POD had considerable high-pressure resistance, and the PPO could be activated by ascorbic acid $(0.2$ to $10 \mathrm{~g} / \mathrm{L})$ during storage (Patras et al., 2009b).Similar results were observed by Chen et al. (2013), which indicated that HHP treated $(600 \mathrm{MPa} / 3 \mathrm{~min})$ apple juice was still detected a residual ( $>50 \%)$ activity of PPO. In another study, after $\mathrm{HHP}$ treatment $\left(450 \mathrm{MPa} / 50^{\circ} \mathrm{C} / 60\right.$ minutes) the residual PPO activity of cloudy apple juice was detected as low as $9.0 \pm 2.2 \%$ (Bayındırlı et al., 2006). The enzyme activity showed a slight downward trend during storage time. At the storage time of week 5, PPO and POD activity decreased by $26 \%$ and $28 \%$, respectively. The changes in enzyme activity of apple juice after HHP treatment may be caused by the more residues of ascorbic acid in CAJ or changes in the secondary and tertiary structures of these enzymes. As reported by JuarezEnriquez et al. (2015), the residual active PPO in juice started recovering its activity during the storage time of 34 days at $4{ }^{\circ} \mathrm{C}$. The conformation changes affect enzyme activity by altering their substrate specificity and function (Han et al., 2019; VallverdúQueralt et al., 2012).

\subsection{Color parameters}

Compared with the untreated juice, the $\mathrm{L}^{\star}$ value of CAJ treated by HTST was decreased $(\mathrm{p}<0.05)$, and that of HHP treatment was close, which indicated the brightness of the CAJ. The $\mathrm{L}^{\star}$ value of HHP treated apple juice decreased faster than that of HTST during storage time (0-5 weeks), possibly due to browning induced by residual PPO and POD enzymes activities. Similar phenomena were observed by Huang et al. (2013), who found that the color of apricot nectar getting darker during storage. Another study found that the $\mathrm{L}^{*}$ value of the HHP-treated cucumber juice tended to decrease during the 20 days storage period, indicating discoloration of the juice (Liu et al., 2016). The $a^{\star}$ value and $b^{\star}$ value of the two treatments were no significant differences. The color of fruit juice is determined to a great extent by the activity of polyphenol oxidase (PPO) and peroxidase (POD) inside. Meanwhile, enzymatic browning occurred in cloudy apple juice has been a severe problem resulting in the lowering of sensorial properties and nutrients. Those browning reactions are initiated by oxidation-reduction enzymes due to degradation of polyphenols to colored quinines, which are substrates to further reactions, leading to pigment formation (Cao et al., 2011; Jukanti, 2017).

\subsection{Antioxidant activities}

The antioxidant capacity (calculated by DPPH and FRAP) of CAJ (data shown in Figure S1 in Supplementary Material), either HTST or HHP treatment, decreased with the prolonging of storage time. Regardless, the antioxidant capacity of HTST samples was generally higher than that of HHP and the untreated samples. These results verified the observations made by (Patras et al., 2009b), who found that the antioxidant activity of the HTST treated $\left(70{ }^{\circ} \mathrm{C} / 2 \mathrm{~min}\right)$ carrot puree was higher than that of the untreated and HHP $\left(400 \mathrm{MPa} / 15 \mathrm{~min} / 20^{\circ} \mathrm{C}\right)$ treated puree. The changes in antioxidant activity of apple juice treated by HHP and HTST are related to the degradation of the polyphenols and ascorbic acid (El Hajj Assaf et al., 2019; Patras et al., 2009a).

\subsection{Polyphenol profiles}

Polyphenolic compounds are believed to be important determining factors of the color, taste and bioactivities of apple juice, as well as influencing its shelf life through browning or co-precipitation with other macromolecules in juice. Figure 1 showed the polyphenol profiles of CAJ treated with HTST or HHP. In this study, nine individual phenolic compounds were quantified in CAJ samples. Compared with the control $(224.80 \mathrm{mg} / \mathrm{L})$ samples, total polyphenol content was significantly phlorizin reduced after HTST (173.80 mg/L) or HHP (127.68 mg/L) treatment.

Chlorogenic acid and phlorizin were typical polyphenolics in apple. HTST induced a higher chlorogenic acid at the beginning of the storage while showed the same content level at the end of the shelf life. As for phlorizin, both HHP and HTST caused a significant decrease $(p<0.05)$ of concentration of CAJ. Flavon-3-ols like catechin and epicatechin showed significant decline $(\mathrm{p}<0.01)$ of content after treatment. Phenolics except caffeic acid, 4-hydroxy benzoic acid and quercetin were detected lower concentration $(\mathrm{p}<0.05)$ after HHP treatment compared with HTST, possibly because PPO and POD the higher $(\mathrm{p}<0.05)$ residual activity in HHP treatment juice, which could oxidize and induce degradation of mono-phenol substances and form polymers. Another explanation is that the extraction property of the plant cell wall was changed due to the destruction of the plant cell wall during heat treatment, making polyphenols more likely to be released (Chen et al., 2013; Huang et al., 2013). The concentration of rutin, quercetin and chlorogenic acid in HTST treatment samples showed a relatively stable content during storage time. Nevertheless, epicatechin in HTST and HHP samples decreased by $33 \%$ and $53 \%$, respectively.

\subsection{Changes on the sensory attributes}

The radar diagram in Figure 2 showed the sensory results of CAJs by different treatments and storage times. There was no significant difference in color and appearance between samples. The scores of aroma and overall acceptability after 
(A)

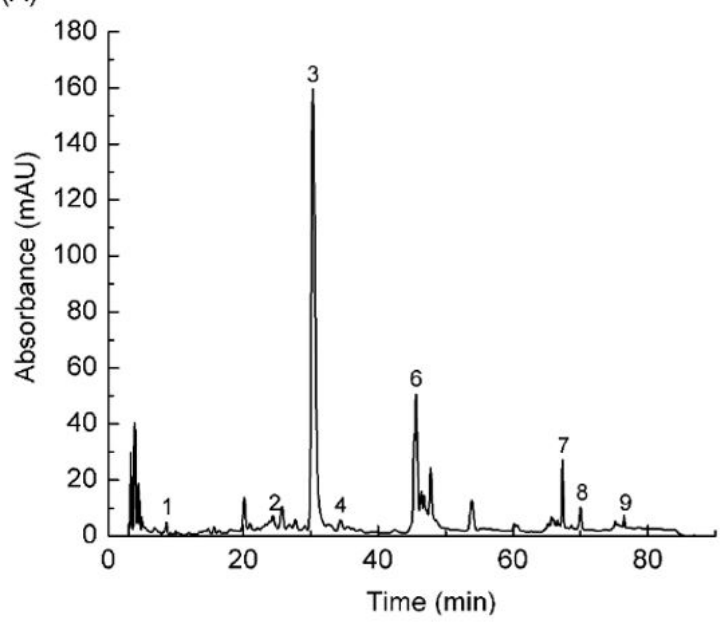

(C)

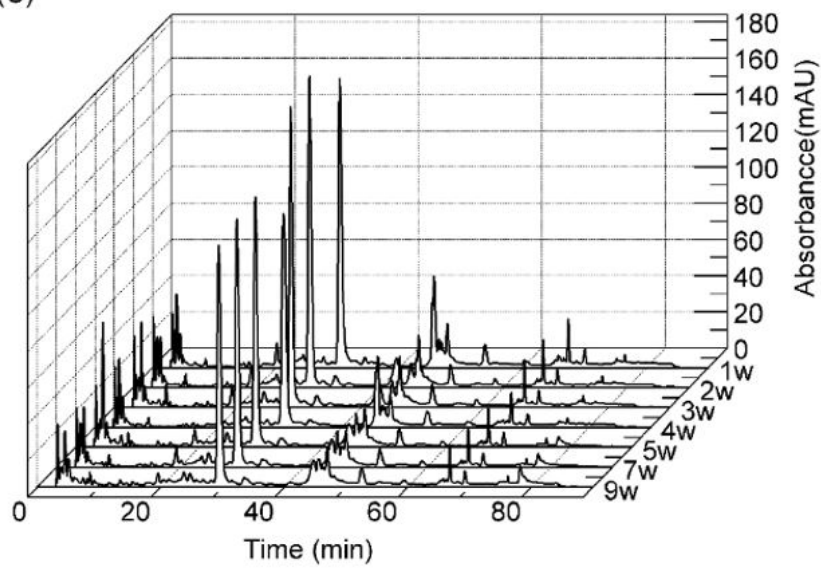

(B)

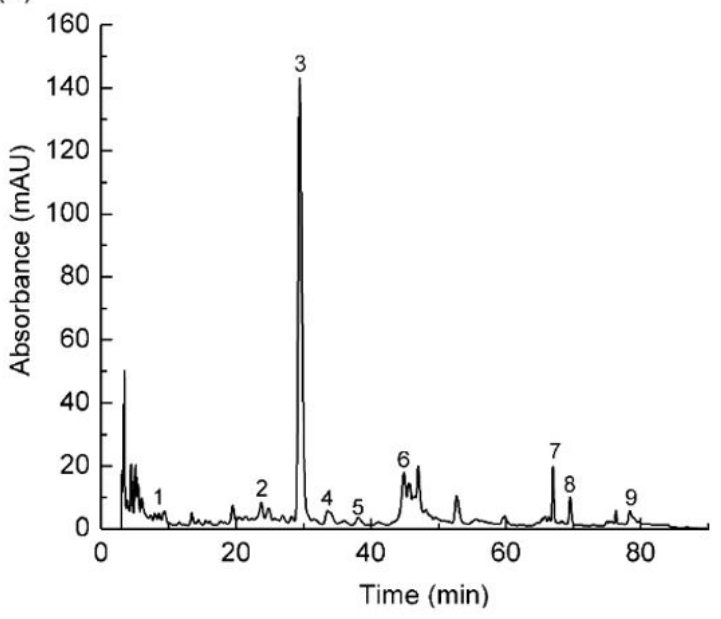

(D)

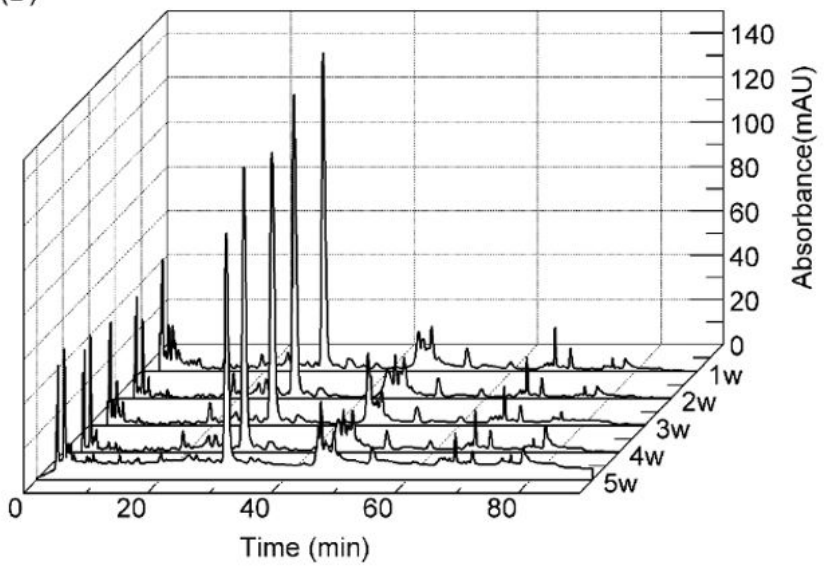

Figure 1. Changes of HPLC chromatogram of the 9 individual phenolic content in cloudy apple juices during storage time at $4{ }^{\circ} \mathrm{C}$ after $\mathrm{HPP}$ and HTST. Chromatogram of the 9 individual phenolic contents in HTST (A) and HHP (B) cloudy apple juice in the first week. The nine monophenolic substances are 1. gallic acid, 2. 4-hydroxybenzoic acid, 3. chlorogenic acid, 4. caffeic acid, 5. catechin, 6. epicatechin, 7. rutin, 8. quercetin, 9. phloridin Chromatogram overlay of the nine individual phenolic contents in HTST (C) and HHP (D) cloudy apple juices over the storage time (1-9 week).

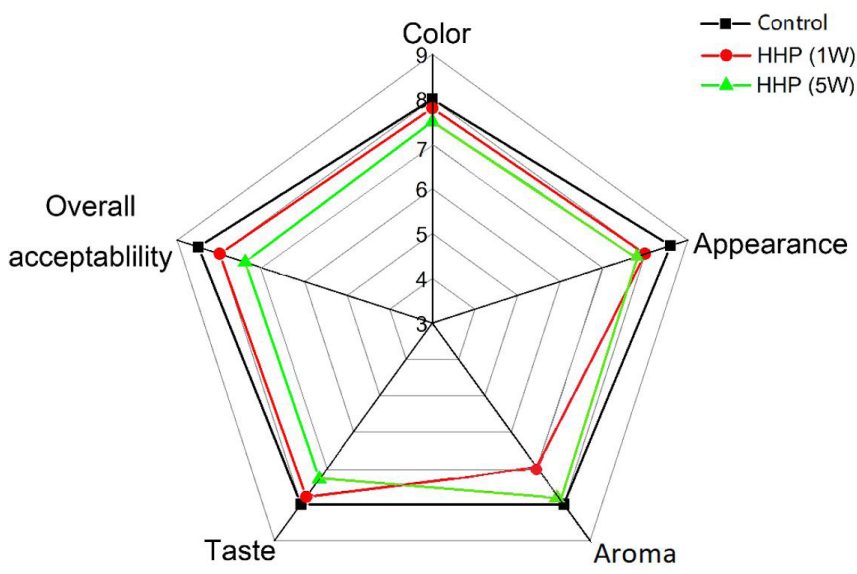

Figure 2. Sensory evaluation of HPP treated cloudy apple juices during storage time $\left(1,5\right.$ week) at $4{ }^{\circ} \mathrm{C}$.
HHP treatment is higher than that of HTST, which explained that HHP was shown to be a better processing technology at maintaining sensory quality. During the storage, both HTST and HHP processing of apple juice showed a slow degradation in the aroma, taste, and overall acceptability aspects, which may due to the physico-chemical changes of polyphenols and odorants of CAJs.

\subsection{Effect of HHP and HTST treatment on the microbial loads}

Spoilage microorganisms are the one of the determinants of juice shelf life. In this study, HHP and HTST treatment both exhibited the capacity of inactivating TAB, Y\&M, and E.coli in cloudy apple juice samples. During the cool storage test, the TAB value of HHP treated juice was detected $(2 \log \mathrm{CFU} / \mathrm{mL})$ at 5 th week. The possible reason is that spores in CAJ had a highresistance form of dormancy, some microorganisms would resume 
growth by self-healing (Bayındırlı et al., 2006) without the high pressure. In comparison, HTST treated CAJ was microbiological safe through the 9-week storage period (Table 2).

\subsection{Microbiological profiles after HHP/HTST treatment, and during cold storage}

Shannon index, Chao 1 index, and ACE index of the bacteria in sample juice were selected to evaluate the microbial richness and diversity in juice samples during cold storage. As can be seen in Figure 3, the Shannon index of HHP1 and HTST1 increased after treatment compared with the control samples, indicating that the microbial diversity of the two kinds of juice increased after treatment. The Chao 1 index and ACE index of HTST1 treated juice rose significantly, indicating a richness and uniformity of the bacterial community at the OTU level.

The Venn diagram visually showed the similarity and specificity of OTU composition in the three samples. The number of OTU identified in CK, HHP1, and HTST1 samples were 546, 423, and
1126, respectively. Compared with HTST, the lower microbial diversity of HHP is probably caused by a lower killing rate of some microorganisms, which consisted of a larger proportion in the bacterial community. In contrast, HTST treatment had a relatively high killing rate of bacteria to kill a wide range of types of bacteria, which gave rise to more diversity of the detected microorganisms. During the storage period, with the increase of the relative abundance of dominant bacteria, the microbial diversity decreased.

The 16s DNA of the bacteria in sample juice was analyzed to identify the main bacteria that cause apple juice to spoil. During the storage period, the bacterial community structure was constantly changing. The information of the top 10 bacteria genera was further mined that dominant bacteria in HHP and HTST treatments cloudy apple juice was different based on phylum (Figure 4A) and genus (4B).

In the control samples, the dominant genera were unconfirmed rickettsia (67.97\%), pseudomonas (5.16\%), and

Table 2. Microbial counts in cloudy apple juice after HTST or HHP treatment during storage period at $4{ }^{\circ} \mathrm{C}(\mathrm{Lg} \mathrm{CFU} / \mathrm{mL})$.

\begin{tabular}{|c|c|c|c|c|c|c|c|c|c|}
\hline \multirow{2}{*}{ Items } & \multirow{2}{*}{ Treatments } & \multicolumn{8}{|c|}{ Storage time (week) } \\
\hline & & 1 & 2 & 3 & 4 & 5 & 7 & 9 & 10 \\
\hline \multirow[t]{3}{*}{ TAB } & Control & $3.41 \pm 0.16^{\mathrm{a}}$ & & & & & & & \\
\hline & HHP & ND & ND & ND & ND & $2.00 \pm 0.18^{\mathrm{b}}$ & & & \\
\hline & HTST & ND & ND & ND & ND & ND & $\mathrm{ND}$ & ND & $3.04 \pm 0.31^{\mathrm{c}}$ \\
\hline \multirow[t]{3}{*}{ Y\&M } & Control & $4.78 \pm 0.11^{\mathrm{a}}$ & & & & & & & \\
\hline & НHP & ND & ND & $\mathrm{ND}$ & $\mathrm{ND}$ & ND & & & \\
\hline & HTST & $\mathrm{ND}$ & ND & ND & $\mathrm{ND}$ & ND & $\mathrm{ND}$ & ND & ND \\
\hline \multirow[t]{3}{*}{ E.coli } & Control & $3.08 \pm 0.07^{\mathrm{a}}$ & & & & & & & \\
\hline & HHP & ND & ND & $\mathrm{ND}$ & ND & ND & & & \\
\hline & HTST & ND & ND & $\mathrm{ND}$ & $\mathrm{ND}$ & ND & $\mathrm{ND}$ & ND & ND \\
\hline
\end{tabular}

${ }^{\star}$ Different lowercase letters indicating significant difference $(\mathrm{p}<0.05)$, "ND" means not determined.
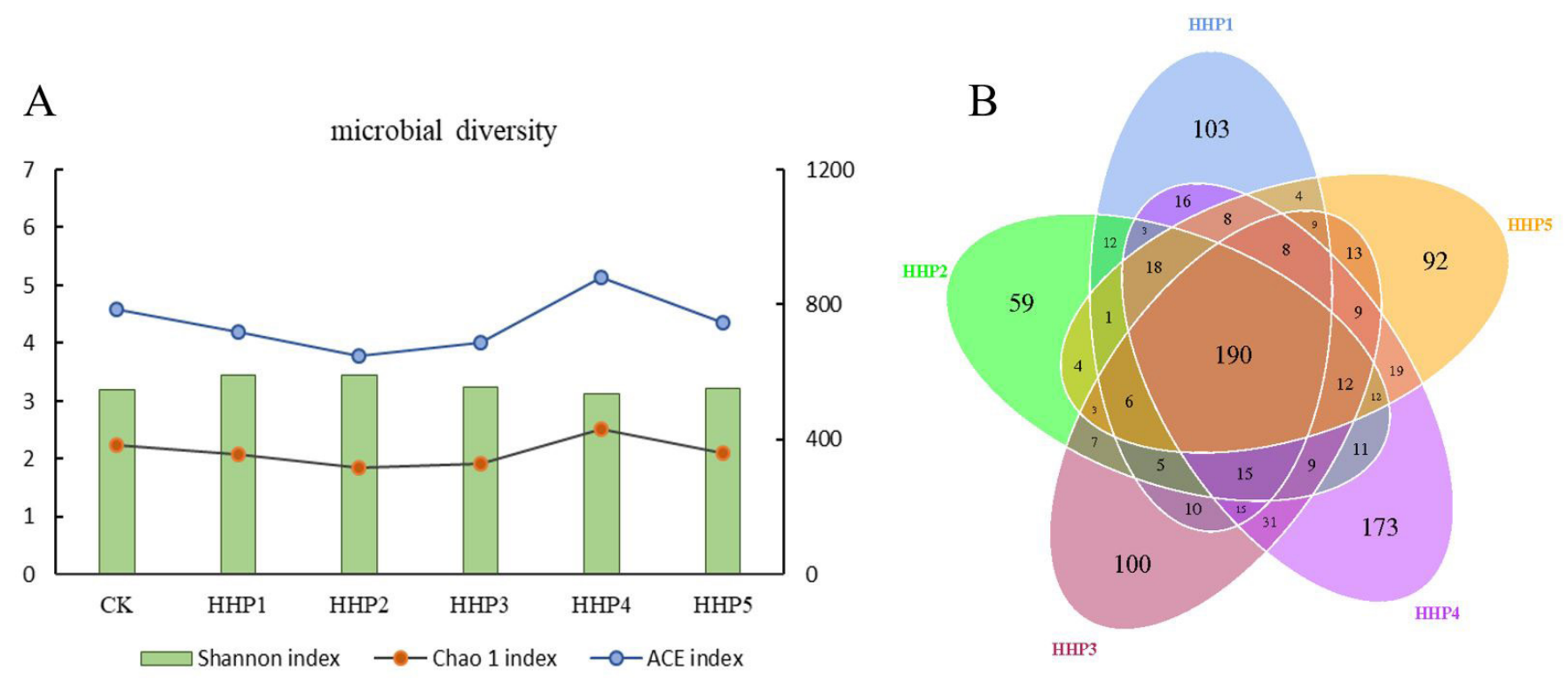

Figure 3. Bacterial diversity of HHP/HTST treated cloudy apple juice under cold storage $\left(4^{\circ} \mathrm{C}\right)$ during $1-9$ week: (A) Shannon index, Chao 1 index, and ACE index; (B) Bacterial OTU-based Venn diagram of HHP treatment samples; HHP with numbers behind means their treatment samples at storage time 1-5 week. 

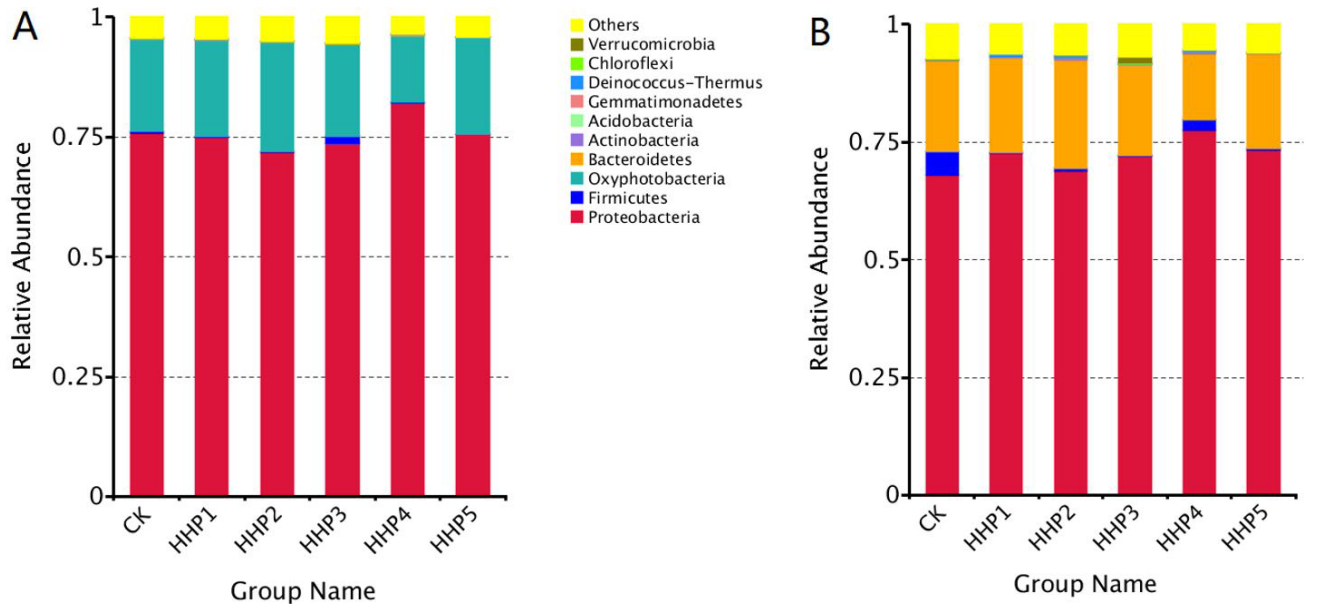

Others
Lactobacillus

Bacteroides

Ralstonia

Phyllobacterium

Faecalibacterium

unidentified_Oxyphotobacteria

Exiguobacterium

Pseudomonas

Oxyphotobacteria

- Firmicutes

Figure 4. Bacterial profiles of HHP treatment apple juice during cold storage $\left(4^{\circ} \mathrm{C}\right)$ during 1-5 weeks. Column atop the cumulative abundance of the top 10 species based on Phylum (A) and Genus (B) level treated by HHP. HHP with numbers behind means their treatment samples at storage time 1-5 week.

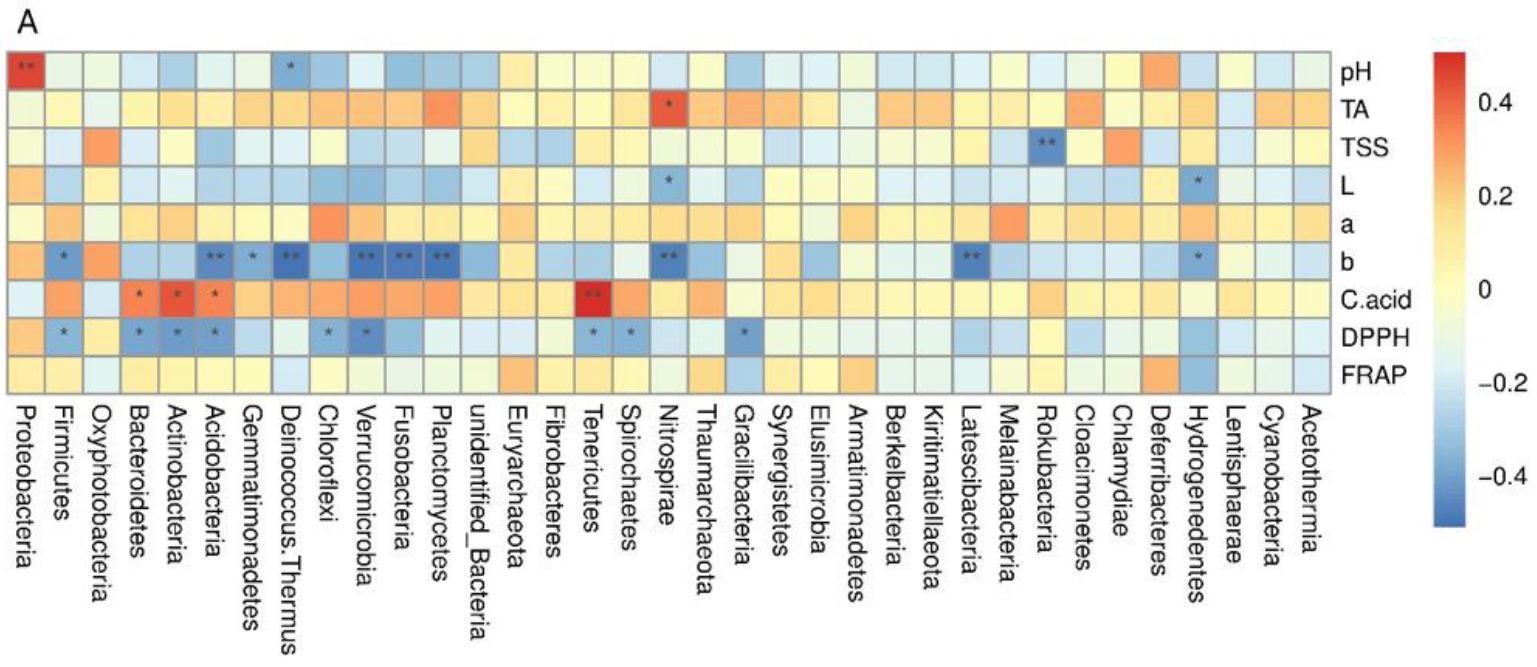

B

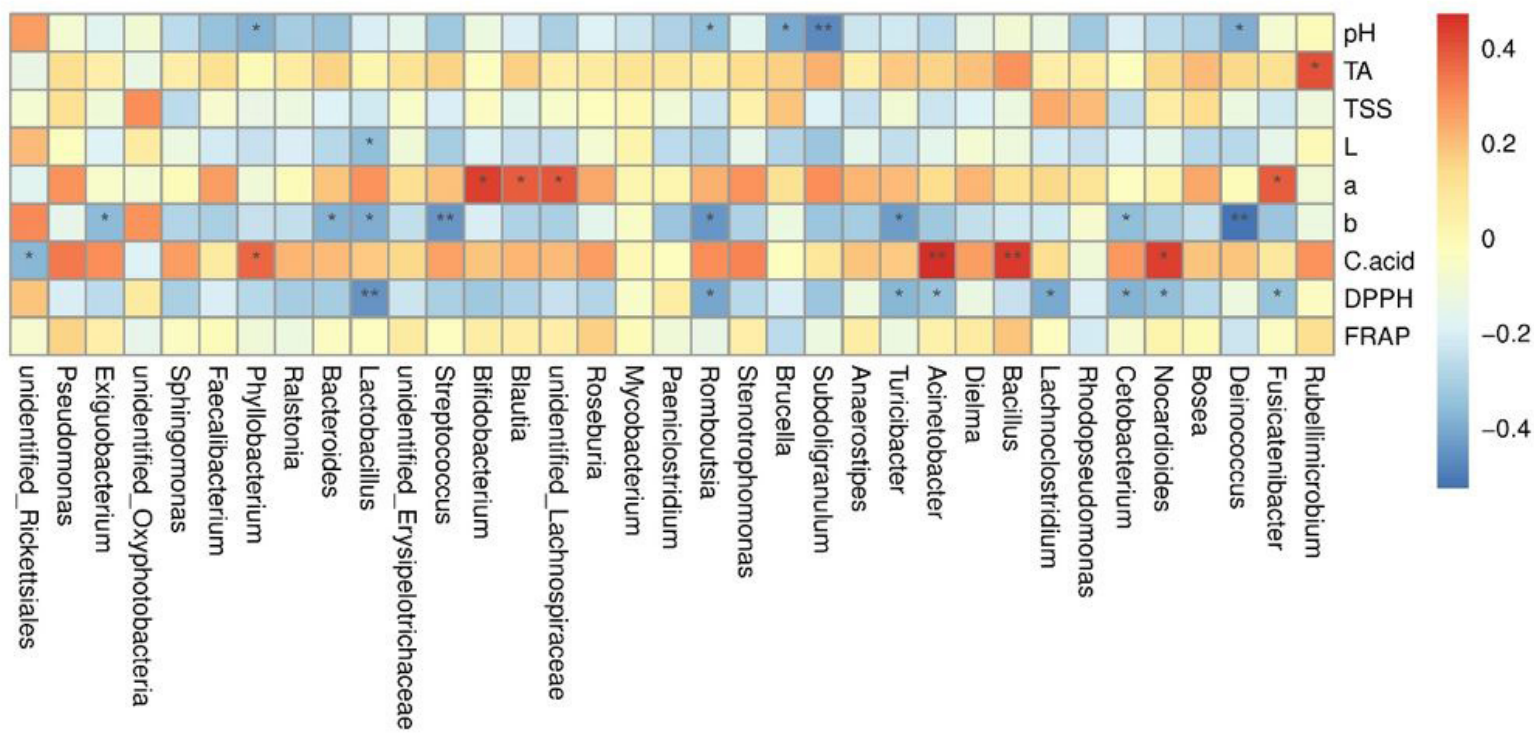

Figure 5. Heatmap for the correlation between microbial species richness at Phylum level (A), genus level (B) of different treatment samples with their physiochemical parameters. 
unconfirmed oxyphotobacteria (19.21\%). After HHP treatment, the dominant genera of juice were unconfirmed rickettsia (72.6\%) and unconfirmed oxyphotobacteria (19.89\%). In comparison, the dominant groups of HTST treatment were unconfirmed pseudomonas (40.28\%), microbacillus (15.69\%) rickettsiella (13.39\%), unconfirmed oxyphotobacteria (10.4\%) and sphingomonas (1.32\%). By the 5th week of cold storage, the relative abundance of unconfirmed rickettsia, unconfirmed photogenic bacteria, and pseudomonas were all higher than that of the 1st week. At the end of storage (week 9), the dominant groups of HTST treated cloudy apple juice were unconfirmed rickettsia, unconfirmed oxyphotobacteria, pseudomonas, sphingomonas, phyllobacterium, cyanobacteria, and bacteroidetes.

\subsection{Correlations between bacterial community and physicochemical parameters}

Spearman correlation analysis was used to test the correlation between physiochemical parameters of all the treatment samples and the richness of 35 bacteria species at Phylum level and Genus level during storage, as displayed in Figure 5. Among the 35 species of bacteria, the species richness were found positively (yellow, orange to red colored squares) correlated to TA, $\mathrm{a}^{*}$ value, content of chlorogenic acid and FRAP; In contrast, a negative (yellow, wathet-blue to blue colored squares) correlation with the parameters of $\mathrm{pH}$, TSS, $\mathrm{L}^{*}$ and $\mathrm{b}^{*}$ values, and DPPH free radicals clearance. What was most remarkable is that chlorogenic acid was found significant positive correlation $(\mathrm{p}<0.05)$ with Tenericutes, Bacteroidetes, Actinomyces, and Acidobacteria at Phylum level, and Acinetobacter, Bacillus, Nocardioides, and Phyllobacterium at Genus level.

\section{Conclusions}

In the present study, we compared the effect of HHP $\left(400 \mathrm{MPa} / 10^{\circ} \mathrm{C} / 10 \mathrm{~min}\right)$ and HTST $\left(98^{\circ} \mathrm{C} / 50 \mathrm{~s}\right)$ treatment on the microbes inactivation, enzymatic activity, phytochemical parameters, and flavor quality during the cold storage. The findings verified that microbial and enzyme inactivation could be achieved after HHP or HTST treatment, which ensured cloudy apple juice 4 weeks and 9 weeks of shelf-life, respectively. Before microbial spoilage occurred in juice, both HHP and HTST treated cloudy apple juice showed a declining trend in aroma, taste and overall acceptability, as well as the $L^{\star}$. Compared with HHP treated cloudy apple juice, HTST treatment had a relatively high killing rate of bacteria and a higher diversity of the detected microorganisms during the cold storage. At the end of shelf-life, the dominant genera were rickettsia, oxyphotobacteria, and pseudomonas in HHP-treated apple juice, and rickettsia, oxyphotobacteria, pseudomonas, sphingomonas, phyllobacterium, cyanobacteria and bacteroidetes in HTST-treated apple juice. Further study is needed to searching for new or improved processing parameters of HHP and HTST technologies, to inactivate the targeted microorganisms especially the spores in CAJs.

\section{Acknowledgements}

The authors thank the apple fruits provided by Luochuan apple experimental station. This research was supported by the National Key Research and Development Program of China (2017YFD0400702).

\section{References}

Abdolmaleki, F., Assadi, M. M., Ezzatpanah, H., \& Honarvar, M. (2014). Impact of fruit processing methods on DNA extraction from transgenic frozen banana products. European Food Research and Technology, 239(3), 509-517. http://dx.doi.org/10.1007/s00217-014-2246-4.

Abid, M., Jabbar, S., Hu, B., Hashim, M. M., Wu, T., Wu, Z. W., Khan, M. A., \& Zeng, X. X. (2014). Synergistic impact of sonication and high hydrostatic pressure on microbial and enzymatic inactivation of apple juice. Lebensmittel-Wissenschaft + Technologie, 59(1), 70-76. http://dx.doi.org/10.1016/j.lwt.2014.04.039.

Alvarez-Sabatel, S., Marañón, I. M., \& Arboleya, J.-C. (2015). Impact of high pressure homogenisation $(\mathrm{HPH})$ on inulin gelling properties, stability and development during storage. Food Hydrocolloids, 44, 333-344. http://dx.doi.org/10.1016/j.foodhyd.2014.09.033.

Baron, A., Dénes, J. M., \& Durier, C. (2006). High-pressure treatment of cloudy apple juice. Lebensmittel-Wissenschaft + Technologie, 39(9), 1005-1013. http://dx.doi.org/10.1016/j.lwt.2006.02.016.

Bayındırlı, A., Alpas, H., Bozoğlu, F., \& Hızal, M. (2006). Efficiency of high pressure treatment on inactivation of pathogenic microorganisms and enzymes in apple, orange, apricot and sour cherry juices. Food Control, 17(1), 52-58. http://dx.doi.org/10.1016/j.foodcont.2004.09.002.

Cao, X. M., Zhang, Y., Zhang, F. S., Wang, Y. T., Yi, J. Y., \& Liao, X. J. (2011). Effects of high hydrostatic pressure on enzymes, phenolic compounds, anthocyanins, polymeric color and color of strawberry pulps. Journal of the Science of Food and Agriculture, 91(5), 877-885. http://dx.doi.org/10.1002/jsfa.4260. PMid:21384355.

Chen, D., Xi, H. P., Guo, X. F., Qin, Z. H., Pang, X. L., Hu, X. S., Liao, X. J., \& Wu, J. H. (2013). Comparative study of quality of cloudy pomegranate juice treated by high hydrostatic pressure and high temperature short time. Innovative Food Science \& Emerging Technologies, 19, 85-94. http://dx.doi.org/10.1016/j.ifset.2013.03.003.

Deng, H., Zhao, X.-X., Xia, Q.-M., Gao, D., Meng, Y.-H., \& Guo, Y.-R. (2015). Analysis and extraction for polyphenols in apple juice of pre- pressing fruit. Science \& Technology of Food Industry, 3, 214-218.

El Hajj Assaf, C., De Clercq, N., Van Poucke, C., Vlaemynck, G., Van Coillie, E., \& Van Pamel, E. (2019). Effects of ascorbic acid on patulin in aqueous solution and in cloudy apple juice. Mycotoxin Research, 35(4), 341-351. http://dx.doi.org/10.1007/s12550-019-00354-y. PMid:31119557.

Gómez-López, V. M., Orsolani, L., Martinez-Yepez, A., \& Tapia, M. S. (2010). Microbiological and sensory quality of sonicated calciumadded orange juice. Lebensmittel-Wissenschaft + Technologie, 43(5), 808-813. http://dx.doi.org/10.1016/j.lwt.2010.01.008.

Han, Y., Cheng, J.-H., \& Sun, D.-W. (2019). Activities and conformation changes of food enzymes induced by cold plasma: A review. Critical Reviews in Food Science and Nutrition, 59(5), 794-811. http://dx.doi. org/10.1080/10408398.2018.1555131. PMid:30799633.

Huang, W. S., Bi, X. F., Zhang, X., Liao, X. J., Hu, X. S., \& Wu, J. H. (2013). Comparative study of enzymes, phenolics, carotenoids and color of apricot nectars treated by high hydrostatic pressure and high temperature short time. Innovative Food Science \& Emerging Technologies, 18, 74-82. http://dx.doi.org/10.1016/j.ifset.2013.01.001.

Illera, A. E., Chaple, S., Sanz, M. T., Ng, S., Lu, P., Jones, J., Carey, E., \& Bourke, P. (2019). Effect of cold plasma on polyphenol oxidase inactivation in cloudy apple juice and on the quality parameters of the juice during storage. Food Chemistry: X, 3, 100049-100049. http://dx.doi.org/10.1016/j.fochx.2019.100049. PMid:31517296.

Juarez-Enriquez, E., Salmeron-Ochoa, I., Gutierrez-Mendez, N., Ramaswamy, H. S., \& Ortega-Rivas, E. (2015). Shelf life studies on apple juice pasteurised by ultrahigh hydrostatic pressure. 
Lebensmittel-Wissenschaft + Technologie, 62(1), 915-919. http:// dx.doi.org/10.1016/j.lwt.2014.07.041.

Jukanti, A. (2017). Polyphenol oxidase(s): importance in food industry. Singapore: Springer Nature.

Katiyo, W., Yang, R. J., \& Zhao, W. (2017). Effects of combined pulsed electric fields and mild temperature pasteurization on microbial inactivation and physicochemical properties of cloudy red apple juice (Malus pumila Niedzwetzkyana (Dieck)). Journal of Food Safety, 37(4), e12369. http://dx.doi.org/10.1111/jfs.12369.

Kim, H. K., Leem, K. H., Lee, S., Kim, B. Y., Hahm, Y. T., Cho, H. Y., \& Lee, J. Y. (2012). Effect of high hydrostatic pressure on immunomodulatory activity of cloudy apple juice. Food Science and Biotechnology, 21(1), 175-181. http://dx.doi.org/10.1007/s10068-012-0022-4.

Liu, F. X., Zhang, X. X., Zhao, L., Wang, Y. T., \& Liao, X. J. (2016). Potential of high-pressure processing and high-temperature/shorttime thermal processing on microbial, physicochemical and sensory assurance of clear cucumber juice. Innovative Food Science \& Emerging Technologies, 34, 51-58. http://dx.doi.org/10.1016/j.ifset.2015.12.030.

Marszalek, K., Szczepanska, J., Starzonek, S., Wozniak, L., Trych, U., Skapska, S., Rzoska, S., Saraiva, J. A., Lorenzo, J. M., \& Barba, F. J. (2019). Enzyme inactivation and evaluation of physicochemical properties, sugar and phenolic profile changes in cloudy apple juices after high pressure processing, and subsequent refrigerated storage. Journal of Food Process Engineering, 42(4). http://dx.doi. org/10.1111/jfpe.13034.

Oszmiański, J., Wojdylo, A., \& Kolniak, J. (2009). Effect of Enzymatic Mash Treatment and Storage on Phenolic Composition, Antioxidant Activity, and Turbidity of Cloudy Apple Juice. Journal of Agricultural and Food Chemistry, 57(15), 7078-7085. http://dx.doi.org/10.1021/ jf900806u. PMid:19572518.

Patras, A., Brunton, N. P., Da Pieve, S., \& Butler, F. (2009a). Impact of high pressure processing on total antioxidant activity, phenolic, ascorbic acid, anthocyanin content and colour of strawberry and blackberry purees. Innovative Food Science \& Emerging Technologies, 10(3), 308-313. http://dx.doi.org/10.1016/j. ifset.2008.12.004.

Patras, A., Brunton, N., Da Pieve, S., Butler, F., \& Downey, G. (2009b). Effect of thermal and high pressure processing on antioxidant activity and instrumental colour of tomato and carrot purees. Innovative
Food Science \& Emerging Technologies, 10(1), 16-22. http://dx.doi. org/10.1016/j.ifset.2008.09.008.

Siguemoto, E. S., Purgatto, E., Hassimotto, N. M. A., \& Gut, J. A. W. (2019). Comparative evaluation of flavour and nutritional quality after conventional and microwave-assisted pasteurization of cloudy apple juice. Lebensmittel-Wissenschaft + Technologie, 111, 853-860. http://dx.doi.org/10.1016/j.lwt.2019.05.111.

Stinco, C. M., Szczepańska, J., Marszałek, K., Pinto, C. A., Inácio, R. S., Mapelli-Brahm, P., Barba, F. J., Lorenzo, J. M., Saraiva, J. A., \& Meléndez-Martínez, A. J. (2019). Effect of high-pressure processing on carotenoids profile, colour, microbial and enzymatic stability of cloudy carrot juice. Food Chemistry, 299, 125112. http://dx.doi.org/10.1016/j.foodchem.2019.125112. PMid:31299521.

Vallverdú-Queralt, A., Odriozola-Serrano, I., Oms-Oliu, G., Lamuela-Raventos, R. M., Elez-Martinez, P., \& Martin-Belloso, O. (2012). Changes in the Polyphenol Profile of Tomato Juices Processed by Pulsed Electric Fields. Journal of Agricultural and Food Chemistry, 60(38), 9667-9672. http://dx.doi.org/10.1021/ jf302791k. PMid:22957841.

Varela-Santos, E., Ochoa-Martinez, A., Tabilo-Munizaga, G., Reyes, J. E., Pérez-Won, M., Briones-Labarca, V., \& Morales-Castro, J. (2012). Effect of high hydrostatic pressure (HHP) processing on physicochemical properties, bioactive compounds and shelf-life of pomegranate juice. Innovative Food Science \& Emerging Technologies, 13(1), 13-22. http://dx.doi.org/10.1016/j.ifset.2011.10.009.

Yen, G. C., Duh, P. D. \& Tsai, H. L. (2002). Antioxidant and pro-oxidant properties of ascorbic acid and gallic acid. Food Chemistry, 79(3), 307-313. https://doi.org/10.1016/S0308-8146(02)00145-0.

Yi, J., Kebede, B. T., Hai Dang, D. N., Buvé, C., Grauwet, T., Van Loey, A., Hu, X., \& Hendrickx, M. (2017). Quality change during high pressure processing and thermal processing of cloudy apple juice. Lebensmittel-Wissenschaft + Technologie, 75, 85-92. http://dx.doi. org/10.1016/j.lwt.2016.08.041.

Zou, H., Lin, T., Bi, X., Zhao, L., Wang, Y., \& Liao, X. (2016). Comparison of high hydrostatic pressure, high-pressure carbon dioxide and high-temperature short-time processing on quality of mulberry juice. Food and Bioprocess Technology, 9(2), 217-231. http://dx.doi. org/10.1007/s11947-015-1606-9. 


\section{Supplementary Material}

Supplementary material accompanies this paper.

Table S1. The standard score sheet for the sensory evaluation of cloudy apple juice.

Table S2. Changes of $\mathrm{pH}$, TA and TSS of CAJ after HTST or HHP treatment during storage period at $4{ }^{\circ} \mathrm{C}$

Figure S1. Changes of DPPH radical scavenging rate (A) and FRAP total antioxidant capacity (B) in cloudy apple juices during storage time at $4{ }^{\circ} \mathrm{C}$ after HHP and HTST.

This material is available as part of the online article from http://www.scielo.br/cta 